\title{
Haemodynamically unstable pulmonary embolism in the RIETE Registry: systolic blood pressure or shock index?
}

\author{
R. Otero*, J. Trujillo-Santos*, A. Cayuelađ, C. Rodríguez*, M. Barron+, J.J. Martín ${ }^{\S}$, \\ M. Monreal ${ }^{f}$ and the Registro Informatizado de la Enfermedad Tromboembólica \\ (RIETE) Investigators**
}

ABSTRACT: Patients with acute pulmonary embolism (PE) presenting with haemodynamic instability have the worst prognosis. However, what is understood by haemodynamic instability has not been clearly defined.

The Registro Informatizado de la Enfermedad Tromboembólica (RIETE) is an ongoing registry of consecutive patients with symptomatic, objectively confirmed, acute deep vein thrombosis or PE. The present authors compared the predictive value of a systolic blood pressure (SBP) value of $<\mathbf{1 0 0} \mathrm{mmHg}$ and $<\mathbf{9 0} \mathrm{mmHg}$ and the shock index (cardiac frequency divided by SBP) on 30day mortality in consecutive patients with PE.

As of May 2006, 6,599 patients with PE were enrolled in the study. Of these, $417(6.3 \%)$ died within 30 days: 153 of the initial PE, 29 of recurrent PE and 235 due to other causes. Of the 417 individuals who died, $127(30 \%)$ had a positive shock index, $60(14 \%)$ had SBP $<100 \mathrm{mmHg}$ and $33(7.9 \%)$ had SBP $<90 \mathrm{mmHg}$. On multivariate analysis any of the three parameters were independently associated with an increased mortality. The shock index had a higher sensitivity (30.5 versus 14.4 and $7.9 \%$ for SBP $<100 \mathrm{mmHg}$ and $<90 \mathrm{mmHg}$, respectively) but lower specificity (86.3 versus 93.0 and 96.6 ).

All three measures of haemodynamic instability are independent predictors of 30-day mortality. However, while the shock index had the highest sensitivity, a systolic blood pressure value $<\mathbf{9 0} \mathbf{m m H g}$ had the highest specificity.

KEYWORDS: Haemodynamic instability, hypotension, prognosis, pulmonary embolism, shock index, survival

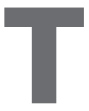

he Seventh American College of Chest Physicians consensus guidelines [1] recommend initial therapy with heparin for patients with acute nonmassive pulmonary embolism (PE), and suggest the use of thrombolytic therapy for those who are haemodynamically unstable. The British Thoracic Society (BTS) guidelines for the management of acute PE [2] recommend outpatient treatment for patients who are clinically stable. The most important criterion to characterise acute PE as massive is systemic arterial hypotension [3]; however, this term is not clearly defined in the literature. Indeed, definitions for haemodynamic instability or massive PE varied among the studies: some used the criterion of a systolic blood pressure (SBP) value $<90 \mathrm{mmHg}[4,5]$; others used SBP $<100 \mathrm{mmHg}$ [6-10]; and others used the shock index (cardiac frequency divided by SBP) [11]. In some studies no definition was provided.
The Registro Informatizado de la Enfermedad Tromboembólica (RIETE) initiative is an ongoing, international (Spain, France, Italy, Israel and Argentina), multicentre, prospective registry of consecutive patients presenting with symptomatic acute venous thromboembolism (VTE) confirmed by objective tests [12-16]. The aim of the present study was to compare the predictive value of the three clinical parameters (shock index, $\mathrm{SBP}<100 \mathrm{mmHg}$ and $\mathrm{SBP}<90 \mathrm{mmHg}$ ) on 30-day mortality in all patients with acute PE.

\section{PATIENTS AND METHODS}

\section{Patient entry criteria}

Participating hospitals in the RIETE Registry (see Acknowledgements) prospectively enrol consecutive patients with symptomatic, acute deep vein thrombosis (DVT) or PE, confirmed by objective tests, as previously reported. All patients provided oral consent to participate in
AFFILIATIONS

*Dept of Pneumonology and

`Research Unit, Virgen del Rocío Hospital, Seville,

\#Dept of Internal Medicine, Santa María del Rosell Hospital, Cartagena, Murcia,

${ }^{+}$Dept of Pneumonology, Hospital Complex San Millán y San Pedro, La Rioja,

${ }^{\S}$ Dept of Pneumonology, University General Hospital Carlos Haya, Málaga,

${ }^{f}$ Dept of Internal Medicine, University Hospital Germans Trias i Pujol, Barcelona, Spain.

${ }^{* *} \mathrm{~A}$ list of RIETE group members is provided in the Acknowledgements.

CORRESPONDENCE

M. Monreal, Servicio de Medicina Interna, Hospital Universitario Germans Trias i Pujol, 08916 Badalona, Barcelona, Spain. Fax: 34934978843 E-mail: mmonreal.germanstrias@ gencat.net

Received:

June 142007

Accepted after revision:

August 222007

\section{SUPPORT STATEMENT}

This project has been partially supported by a Red Respira grant (RedRespira-ISCiii-RTIC-03/11) from the Instituto de Salud Carlos III (Madrid, Spain).

STATEMENT OF INTEREST A statement of interest for this study can be found at

www.erj.ersjournals.com/misc/ statements.shtml

European Respiratory Journal Print ISSN 0903-1936 Online ISSN 1399-3003 
the Registry, according to the requirements of the ethics committee within each hospital.

\section{Study end-points}

The primary end-point was defined as a 1-month mortality. SBP and cardiac frequency were measured at presentation to the emergency department, and the shock index (cardiac frequency divided by SBP) was calculated in all PE patients for further stratification. A positive shock index was defined as $\geqslant 1$ (haemodinamically unstable patients) and a negative shock index as $<1$ (haemodinamically stable patients).

\section{Study variables and definitions}

The following parameters were recorded: baseline characteristics; clinical status, including any coexisting or underlying conditions, such as chronic heart or lung disease; risk factors for PE; type and dose of treatment received upon PE diagnosis; and outcome during the first 30 days of therapy. Immobilised patients are defined in the present analysis as nonsurgical patients who had been immobilised (i.e. total bed rest with bathroom privileges) for $\geqslant 4$ days in the 2-month period prior to $\mathrm{PE}$ diagnosis. Surgical patients are defined as those who had undergone an operation in the 2 months prior to VTE diagnosis. Creatinine clearance was estimated with the formula by COCKCROFT and GAULT [17]. The first creatinine measured after $\mathrm{PE}$ diagnosis was used to calculate creatinine clearance. The causes of death were determined by the attending physicians. In case of doubt, the case report was addressed to the Adjudication Committee of the RIETE Registry.

\section{Statistical analysis}

A p-value $<0.05$ was considered to be statistically significant. First, the influence of a number of variables on the risk of 1week and 30-day mortality was tested by bivariate analysis with Chi-squared test. Candidate variables were based on published literature. Multivariate analysis was carried out using a logistic regression analysis in the former case and a Cox proportional hazard analysis in the latter, in order to identify predictors of mortality and the independence of the three variables. Then, a receiver operating characteristic (ROC) curve analysis was performed [18]. Finally, the sensitivity, specificity, and positive and negative predictive values were compared in order to assess the accuracy of the three variables to predict mortality.

\section{RESULTS}

As of May 2006, 6,599 consecutive patients with acute, symptomatic PE had enrolled in RIETE: 3,042 males and 3,557 females, aged 14-99 yrs (mean 68 yrs). PE diagnosis was confirmed in 4,138 patients with a positive computed tomography scan, 2,801 with a high-probability ventilationperfusion lung scan, 69 with a positive angiogram, 36 with visualisation of a thrombus on the echocardiogram and 124 patients with intermediate-probability lung scan plus evidence of DVT in the lower limbs.

A total of 417 (6.3\%) patients died during the first 30 days. The causes of death were: the initial PE event in 153 (37\%) patients; recurrent $\mathrm{PE}$ in 29 (7.0\%); and other causes in $235(56 \%)$ patients. Of the 417 patients who died, $127(30 \%)$ had a positive shock index, 60 (14\%) had SBP $<100 \mathrm{mmHg}$ and 33 (7.9\%) had $\mathrm{SBP}<90 \mathrm{mmHg}$.
The patients who died were significantly older, more often inpatients and weighed less than those who survived (table 1). More often they also had cancer, immobility for $\geqslant 4$ days, renal insufficiency, chronic heart failure or recent major bleeding, but less often, a prior episode of VTE or recent surgery. As for their clinical presentation, patients who died were more often those who had tachycardia, hypotension, atrial fibrillation or hypoxaemia at presentation. On multivariate analysis, the hazard ratios $(95 \%$ confidence interval (CI)) for 1-month mortality were 2.3 (1.5-3.6) for positive shock index, 1.6 (1.02.5) for SBP $<100 \mathrm{mmHg}$ and 1.7 (0.9-3.2) for SBP $<90 \mathrm{mmHg}$, as shown in table 2 and in figures 1-3.

The shock index had a higher sensitivity than either SBP $<100 \mathrm{mmHg}$ or SBP $<90 \mathrm{mmHg}$ but a lower specificity, as shown in table 3 . There were no significant differences in sensitivity, specificity and positive or negative predictive value, whether the cause of death was the initial PE event,

\begin{tabular}{|c|c|c|c|c|}
\hline \multirow[t]{2}{*}{ TABLE 1} & \multirow[b]{2}{*}{ Dead } & \multirow[b]{2}{*}{ Alive } & \multirow[b]{2}{*}{ OR (95\% Cl) } & \multirow[b]{2}{*}{ p-value } \\
\hline & & & & \\
\hline Subjects n & 417 & 6182 & & \\
\hline \multicolumn{5}{|l|}{ Clinical characteristics } \\
\hline Males & $187(45)$ & $2855(46)$ & $0.9(0.8-1.2)$ & NS \\
\hline Age $>70$ yrs & $314(75)$ & $3533(57)$ & $2.3(1.8-2.9)$ & $<0.001$ \\
\hline Body weight $<65 \mathrm{~kg}$ & $186(45)$ & $1486(24)$ & $2.5(2.1-3.1)$ & $<0.001$ \\
\hline Outpatients & $284(68)$ & $4526(73)$ & $0.8(0.6-0.9)$ & 0.007 \\
\hline \multicolumn{5}{|l|}{ Risk factors for VTE } \\
\hline Previous VTE & $40(9.0)$ & $968(16)$ & $0.6(0.4-0.8)$ & 0.001 \\
\hline Cancer & $178(43)$ & 1104 (18) & $3.4(2.8-4.2)$ & $<0.001$ \\
\hline Surgery & $35(8.4)$ & $887(14)$ & $0.5(0.4-0.8)$ & $<0.001$ \\
\hline Immobility $\geqslant 4$ days & $192(46)$ & $1507(24)$ & $2.6(2.2-3.2)$ & $<0.001$ \\
\hline \multicolumn{5}{|l|}{ Underlying diseases } \\
\hline $\mathrm{CrCl}<30 \mathrm{~mL} \cdot \mathrm{min}^{-1}$ & $86(21)$ & $357(5.8)$ & $4.2(3.3-5.5)$ & $<0.001$ \\
\hline Chronic lung disease & $64(15)$ & $830(13)$ & $1.2(0.9-1.5)$ & NS \\
\hline Chronic heart failure & $57(14)$ & $471(7.6)$ & $1.9(1.4-2.6)$ & $<0.001$ \\
\hline Recent major bleeding & $26(6.2)$ & $150(2.4)$ & $2.7(1.7-4.1)$ & $<0.001$ \\
\hline \multicolumn{5}{|l|}{ Clinical presentation } \\
\hline $\begin{array}{l}\text { Cardiac frequency } \\
>100 \text { bpm }\end{array}$ & $239(57)$ & $2463(40)$ & $2.0(1.7-2.5)$ & $<0.001$ \\
\hline Positive shock index & 127 (31) & $848(14)$ & $2.8(2.2-3.4)$ & $<0.001$ \\
\hline $\mathrm{SBP}<100 \mathrm{mmHg}$ & $60(14)$ & $433(7.0)$ & $2.2(1.7-3.0)$ & $<0.001$ \\
\hline $\mathrm{SBP}<90 \mathrm{mmHg}$ & $33(7.9)$ & $208(3.4)$ & $2.5(1.7-3.6)$ & $<0.001$ \\
\hline Atrial fibrillation ${ }^{\#}$ & $59(17)$ & $556(9.8)$ & $1.8(1.4-2.4)$ & $<0.001$ \\
\hline $\mathrm{Pa}_{1} \mathrm{O}_{2}<60 \mathrm{mmHg}$ & $200(59)$ & 2079 (42) & $2.0(1.6-2.5)$ & $<0.001$ \\
\hline \multicolumn{5}{|l|}{ Initial therapy } \\
\hline LMWH & $349(84)$ & $5167(84)$ & $1.0(0.8-1.3)$ & NS \\
\hline UFH & $49(12)$ & $856(14)$ & $0.8(0.6-1.1)$ & NS \\
\hline Thrombolytics & $15(3.6)$ & $127(2.1)$ & $1.8(1.0-3.1)$ & NS \\
\hline Inferior vena cava filter & $15(3.6)$ & $142(2.3)$ & $1.6(0.9-2.7)$ & NS \\
\hline
\end{tabular}


TABLE 2 Multivariate analysis (Cox proportional hazard models) on the risk of death at 30 days

\begin{tabular}{|c|c|c|c|c|c|c|}
\hline & OR $(95 \% \mathrm{Cl})$ & $\mathrm{p}$-value & OR $(95 \% \mathrm{Cl})$ & $\mathrm{p}$-value & OR (95\% Cl) & $p$-value \\
\hline Age $>70$ yrs & $1.8(1.4-2.4)$ & $<0.001$ & $1.7(1.3-2.3)$ & $<0.001$ & $1.7(1.3-2.3)$ & $<0.001$ \\
\hline Body weight $<65 \mathrm{~kg}$ & $1.8(1.4-2.3)$ & $<0.001$ & $1.9(1.5-2.3)$ & $<0.001$ & $1.9(1.5-2.4)$ & $<0.001$ \\
\hline Previous VTE & $0.6(0.4-0.8)$ & 0.005 & $0.6(0.4-0.8)$ & 0.005 & $0.6(0.4-0.8)$ & 0.004 \\
\hline $\mathrm{CrCl}<\mathbf{3 0} \mathrm{mL} \cdot \mathrm{min}^{-1}$ & $2.5(1.9-3.4)$ & $<0.001$ & $2.4(1.8-3.3)$ & $<0.001$ & $2.5(1.9-3.3)$ & $<0.001$ \\
\hline 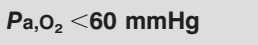 & $1.5(1.2-1.9)$ & 0.001 & $1.6(1.2-2.0)$ & $<0.001$ & $1.6(1.2-2.0)$ & $<0.001$ \\
\hline Positive shock index & $2.4(1.9-3.0)$ & $<0.001$ & & & & \\
\hline $\mathrm{SBP}<\mathbf{1 0 0} \mathbf{m m H g}$ & & & $1.6(1.1-2.2)$ & 0.005 & & \\
\hline $\mathrm{SBP}<\mathbf{9 0} \mathbf{m m H g}$ & & & & & $1.5(0.9-2.3)$ & 0.08 \\
\hline
\end{tabular}

recurrent $\mathrm{PE}$ or other reasons (table 3 ). The area under the ROC curve $(95 \% \mathrm{CI})$ was 0.79 (0.77-0.82) for the positive shock index, $0.78(0.75-0.80)$ for SBP $<100 \mathrm{mmHg}$ and $0.77(0.75-$ $0.80)$ for $\mathrm{SBP}<90 \mathrm{mmHg}$.

\section{DISCUSSION}

The present data, obtained from a large prospective series of consecutive patients in the RIETE Registry, confirm that any of the three mentioned parameters (shock index, SBP $<100 \mathrm{mmHg}$ and SBP $<90 \mathrm{mmHg}$ ) are independent predictors of 30-day mortality in patients with acute PE. The observation that haemodynamic instability at presentation predicts an adverse outcome in acute PE is certainly not new but confirms previous data from recent decades [3-11]. In the present authors' experience, the three shock parameters examined are equally good (or equally inadequate) in predicting an adverse outcome, since they all appear significant in the Cox model but do not possess high sensitivity or specificity. However, some

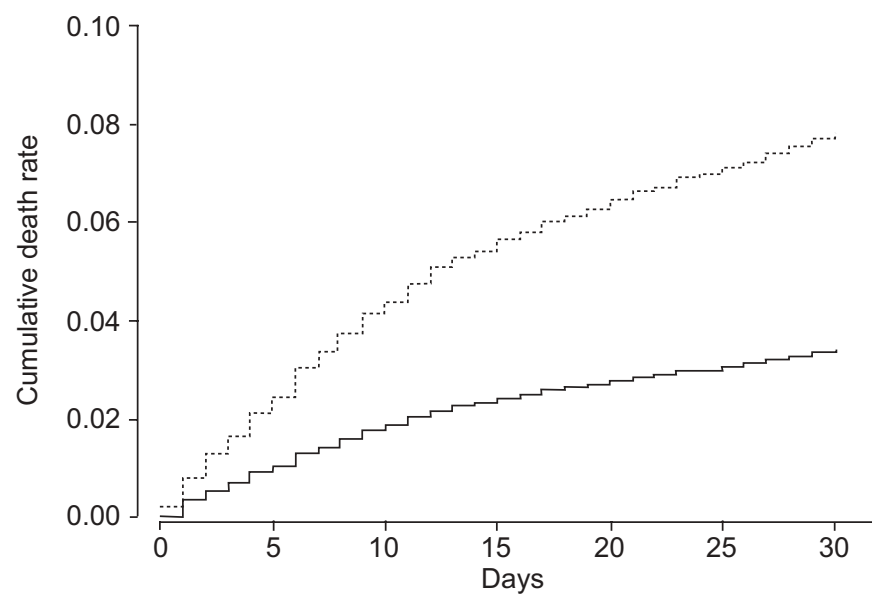

FIGURE 1. Kaplan-Meier survival curves using the Cox model for patients with $(\cdots \cdots \cdot$ : shock index $\geqslant 1.0)$ and without $(-$ : shock index $<1.0)$ positive shock index. differences were found among them in terms of sensitivity and specificity that may be relevant in clinical practice.

Two of the most controversial and unsolved issues in the treatment of acute PE are the selection of patients for outpatient therapy and the role of thrombolysis. There is growing evidence that outpatient therapy with low-molecular weight heparin is effective and safe for most patients with PE $[19,20]$. Based on this evidence, the BTS guidelines for the management of acute $\mathrm{PE}$ [2] recommend outpatient treatment for clinically stable patients. However, this was not defined. Of the 417 patients who died in the current series, $30 \%$ had a positive shock index and $7.9 \%$ had SBP $<90 \mathrm{mmHg}$. This higher sensitivity of the shock index makes it more useful when trying to identify a subgroup of patients at low risk of death. Of course, the shock index alone is not sensitive or specific enough to decide which candidates should receive home therapy but, combined with other independent variables (i.e. age, body weight, immobility,

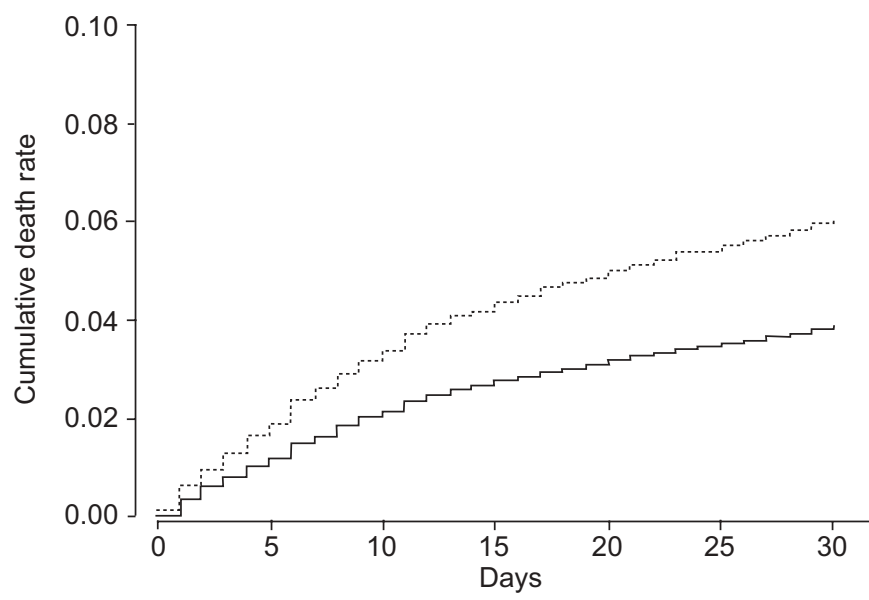

FIGURE 2. Kaplan-Meier survival curves using the Cox model for patients with $(\cdots . .$.$) and without (-)$ systolic blood pressure $<100 \mathrm{mmHg}$. 


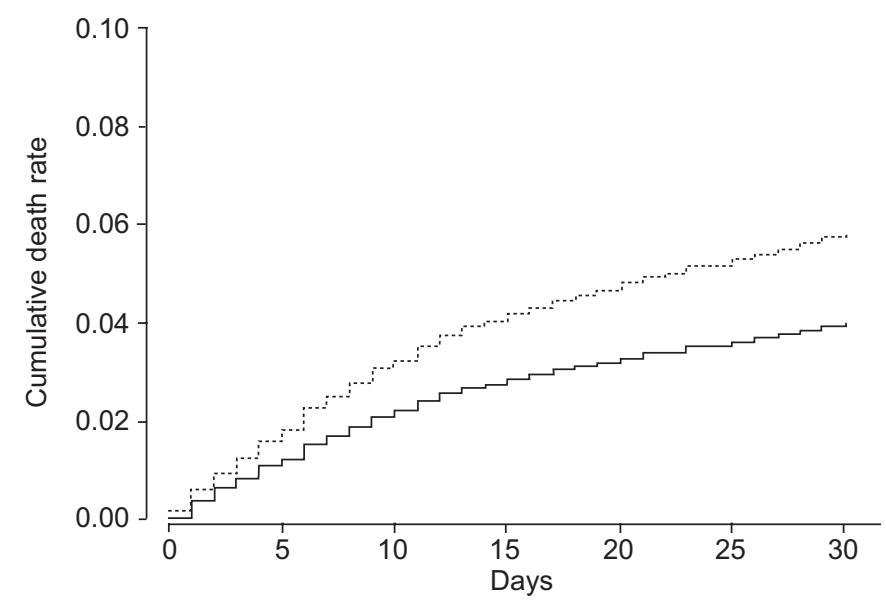

FIGURE 3. Kaplan-Meier survival curves using the Cox model for patients with $(\cdots \cdots)$ and without $(-)$ systolic blood pressure $<90 \mathrm{mmHg}$.

cancer, hypoxaemia or renal insufficiency), it should be preferred over SBP alone.

In the other extreme, the benefit of thrombolysis or other aggressive therapies over heparin appears only in PE patients at high risk for death [21-27]. However, since thrombolytic therapy doubles the risk for major bleeding [21], careful and rapid risk assessment is paramount in selecting the appropriate treatment strategy in these patients. In the current study, only $3.4 \%$ of those who survived had SBP $<90 \mathrm{mmHg}$, while $14 \%$ had a positive shock index. In the present authors' opinion, this higher specificity of SBP $<90 \mathrm{mmHg}$ would better help identify the subgroup of patients at high risk for death.

The present study has some limitations. First, the $6.3 \%$ death rate in the current series is slightly lower than the $5.0-15 \%$ rates observed in other studies $[6,7,11,28,29]$. These differences may be attributed to either different observation periods (30 days in the present study) or the need for objective confirmation of PE diagnosis in RIETE. Some patients with severe PE may have died before getting an objective confirmation or were not enrolled as they could not give informed consent. Secondly, the shock index, as a ratio, is subject to many problems (e.g. inappropriate relative bradycardia with a low SBP can still give a patient a positive shock index, clearly undesirable). Thirdly, although the shock index had a higher sensitivity than either of the SBP parameters, it remains quite low $(30.5 \%)$, and the positive predictive values are very low and very close. Thus, a negative shock index does not guarantee an uncomplicated hospital course since the overall mortality rate at 30 days in these patients was $5.2 \%$ (95\% CI 4.6-5.8). Physicians should also consider the utility of other methods to detect patients at high risk of dying (i.e. echocardiography, cardiac biomarkers). Finally, as an observational study, RIETE is not designed to answer questions regarding the relative efficacy and safety of different modalities of therapy. Data from the Registry are hypothesis generating and provide feedback from real-world clinical situations which may be of value when designing new randomised clinical studies.

\begin{tabular}{|c|c|c|c|c|}
\hline \multirow[t]{3}{*}{ TABLE 3} & \multicolumn{4}{|c|}{$\begin{array}{l}\text { Predictive value of the three variables in the } \\
\text { prediction of } 30 \text {-day mortality }\end{array}$} \\
\hline & & \multirow{2}{*}{$\begin{array}{l}\text { Positive shock } \\
\text { index }\end{array}$} & \multicolumn{2}{|c|}{ SBP } \\
\hline & & & $<100 \mathrm{mmHg}$ & $<90 \mathrm{mmHg}$ \\
\hline \multicolumn{5}{|c|}{ Overall death ${ }^{\#}$} \\
\hline Patients & & $127(30)$ & $60(14)$ & $33(7.9)$ \\
\hline Sensitivity & & $30.5(26.2-35.0)$ & $14.4(11.3-18.1)$ & $7.9(5.7-10.9)$ \\
\hline Specificity & & $86.3(85.4-87.1)$ & 93.0 (92.3-93.6) & $96.6(96.2-97.1)$ \\
\hline PPV & & $13.0(11.1-15.3)$ & $12.2(9.6-15.4)$ & $13.7(9.9-18.6)$ \\
\hline NPV & & $94.8(94.2-95.4)$ & $94.2(93.5-94.7)$ & $94.0(93.3-94.5)$ \\
\hline \multicolumn{5}{|c|}{ Fatal, initial PE ${ }^{\bullet}$} \\
\hline Patients & & 49 (32) & $24(16)$ & $16(10)$ \\
\hline Sensitivity & & $32.0(25.2-39.8)$ & $15.7(10.8-22.3)$ & $10.5(6.5-16.3)$ \\
\hline Specificity & & $85.6(84.8-86.5)$ & 92.7 (92.1-93.3) & 96.5 (96.0-96.9) \\
\hline PPV & & $5.0(3.8-6.6)$ & $4.9(3.3-7.1)$ & $6.6(4.1-10.5)$ \\
\hline NPV & & $98.2(97.8-98.5)$ & $97.9(97.5-98.2)$ & $97.8(97.5-98.2)$ \\
\hline \multicolumn{5}{|c|}{ Fatal, recurrent $\mathrm{PE}^{+}$} \\
\hline Patients & & $10(34)$ & $4(14)$ & $1(3.4)$ \\
\hline Sensitivity & & $34.5(19.9-52.7)$ & $13.8(5.5-30.6)$ & $3.4(0.6-17.2)$ \\
\hline Specificity & & $85.3(84.4-86.1)$ & 92.6 (91.9-93.2) & $96.3(95.9-96.8)$ \\
\hline PPV & & $1.0(0.6-1.9)$ & $0.8(0.3-2.1)$ & $0.4(0.1-2.3)$ \\
\hline NPV & & $99.7(99.5-99.8)$ & $99.6(99.4-99.7)$ & $99.6(99.4-99.7)$ \\
\hline \multicolumn{5}{|c|}{ Death, other reasons ${ }^{5}$} \\
\hline Patients & & $68(29)$ & $32(14)$ & $16(6.8)$ \\
\hline Sensitivity & & $28.9(23.5-35.0)$ & $13.6(9.8-18.6)$ & $6.8(4.2-10.8)$ \\
\hline Specificity & & 85.7 (84.9-86.6) & $92.8(92.1-93.4)$ & 96.5 (96.0-96.9) \\
\hline PPV & & $7.0(5.5-8.7)$ & $6.5(4.6-9.0)$ & $6.6(4.1-10.5)$ \\
\hline NPV & & $97.0(96.6-97.4)$ & $96.7(96.2-97.1)$ & $96.6(96.1-97.0)$ \\
\hline
\end{tabular}

Data are presented as $\mathrm{n}(\%)$ or odds ratio (95\% confidence interval). SBP: systolic blood pressure; PPV: positive predictive value; NPV: negative predictive value; PE: pulmonary embolism. ${ }^{*}: \mathrm{n}=417 ;{ }^{\bullet}: \mathrm{n}=153{ }^{+}: \mathrm{n}=29{ }^{\mathrm{s}}{ }^{\mathrm{s}} \mathrm{n}=235$.

In summary, all three measures of haemodynamic instability are independent predictors of 30-day mortality. This issue is important since these criteria are used when deciding whether a patient with acute pulmonary embolism should be hospitalised or receive thrombolytic therapy. Given their low positive predictive value, they are not particularly predictive of a poor outcome but their absence is highly predictive of a good outcome (given their high negative predictive value). Interestingly, this was true whether the patients died of pulmonary embolism or another cause. Although a shock index of $>1$ was more sensitive and an systolic blood pressure $<90 \mathrm{mmHg}$ more specific, these statistically significant differences were not very important in clinical meaningful terms.

\section{ACKNOWLEDGEMENTS}

The members of the RIETE group are as follows.

Spain. Albacete: J.L. Beato (Hospital de Hellín); Alicante: L. Hernández (Hospital General Universitario de Alicante), A. Maestre (Hospital General Universitario de Elche, Elche); Asturias: I. López (Hospital San Agustín, Avilés); Barcelona: C. Falgá (Consorci Hospitalari de Mataró), M. Monreal (Hospital Universitari Germans Trias i Pujol, Badalona), E. 
Raguer (Hospital de Terrassa), A. Raventos (Hospital Municipal de Badalona), C. Tolosa (Corporació Sanitària Parc Taulí, Sabadell), M. Valdés (Hospital de Viladecans); Cáceres: J.M. Calvo (Hospital Ciudad de Coria), J.F. Sánchez (Hospital San Pedro de Alcántara); Ciudad Real: J. Portillo (Complejo Hospitalario de Ciudad Real); Córdoba: A. Blanco (Hospital Universitario Reina Sofía), L. López (Hospital Provincial Reina Sofía); Cuenca: J.A. Nieto (Hospital General Virgen de la Luz, Cuenca); Gerona: F. García-Bragado (Hospital Universitari Dr Josep Trueta), S. Soler (Hospital Sant Jaume, Olot); Granada: J.I. Arcelus, I. Casado (Hospital Universitario Virgen de las Nieves); Logroño: M. Barrón (Complejo Hospitalario San Millán y San Pedro); Madrid: R. Barba (Fundación Hospital Alcorcón), C. Fernández-Capitán (Hospital Universitario La Paz), J. Gutiérrez (Hospital Monográfico Asepeyo, Coslada), D. Jiménez (Hospital Ramón y Cajal), O. Madridano (Hospital Universitario La Paz), N. Ruiz-Giménez (Hospital Universitario de la Princesa); Lugo: R. Rabuñal (Complexo Hospitalario Xeral-Calde); Málaga: R. Guijarro, J.J. Martín (Hospital General Universitario Carlos Haya), M. Guil (Hospital Comarcal de la Axarquía, Vélez-Málaga); Murcia: J. Trujillo (Hospital General Santa María del Rosell, Cartagena); Pamplona: R. Lecumberri (Clínica Universitaria de Navarra), M.T. Orue (Hospital de Navarra), G. Tiberio (Hospital Virgen del Camino); Pontevedra: J. Montes (Hospital de Meixoeiro, Vigo), M.J. Núñez (Hospital Comarcal do Salnés, Vilagarcía de Arousa); Santander: R. Valle (Hospital Sierrallana, Torrelavega); Sevilla: R. Otero (Hospital Virgen del Rocío); Tarragona: L. Font (Hospital de Tortosa Vergel de la Cinta, Tortosa); Teruel: J. Vela (Hospital de Alcañiz); Valencia: F. López (Hospital Arnau de Vilanova, Arnau de Vilanova), M.D. Naufall, J.A. Todolí (Hospital Universitario La Fe), P. Román (Hospital General de Requena); Vizcaya: F. Uresandi (Hospital de Cruces); Zaragoza: F. Conget (Hospital Clínico).

France. Saint-Etienne: P. Mismetti, K. Rivron-Guillot (Hospital Bellevue).

Italy. Genoa: R. Poggio (Ospedale Galliera); Naples: P. Di Micco, M.T. Iannuzo (Ospedale Buonconsiglio Fatebenefratelli); Padua: P. Prandoni (Clinica Medical Il University of Padua); Parma: R. Quintavalla (Azienda Ospedaliera Universitaria); Rimini: E. Tiraferri (Ospedale Infermi).

The authors would like to thank S. Ortiz (Universidad Autónoma de Madrid and S\&H Medical Science Service; both Madrid, Spain) for statistical analysis of the data and the Registry Coordinating Centre (S\&H Medical Science Service) for logistic and administrative support.

\section{REFERENCES}

1 Büller HR, Agnelli G, Hull RD, Hyers TM, Prins MH, Raskob GE. Antithrombotic therapy for venous thromboembolic disease: the Seventh ACCP Conference on Antithrombotic and Thrombolytic Therapy. Chest 2004; 126: Suppl. 3, 401S-428S.

2 British Thoracic Society Standards of Care Committee Pulmonary Embolism Guideline Development Group. British Thoracic Society guidelines for the management of suspected acute pulmonary embolism. Thorax 2003; 58: 470-483.

3 Kucher N, Rossi E, De Rosa M, Goldhaber SZ. Massive pulmonary embolism. Circulation 2006; 113: 577-582.

4 Kucher N, Goldhaber SZ. Management of massive pulmonary embolism. Circulation 2005; 112: e28-e32.

5 Kucher N, Rossi E, De Rosa M, Goldhaber SZ. Prognostic role of echocardiography among patients with acute pulmonary embolism and a systolic arterial pressure of $90 \mathrm{mmHg}$ or higher. Arch Intern Med 2005; 165: 1777-1781.

6 Wicki J, Perrier A, Perneger TV, Bounameaux H, Junod AF. Predicting adverse outcome in patients with acute pulmonary embolism: a risk score. Thromb Haemost 2000; 84: 548-552.

7 Nendaz MR, Bandelier P, Aujesky D, et al. Validation of a risk score identifying patients with acute pulmonary embolism, who are at low risk of clinical adverse outcome. Thromb Haemost 2004; 91: 1232-1236.

8 Aujesky D, Obrosky DS, Stone RA, et al. Derivation and validation of a prognostic model for pulmonary embolism. Am J Respir Crit Care Med 2005; 172: 1041-1046.

9 Aujesky D, Roy PM, Le Manach CP, et al. Validation of a model to predict adverse outcomes in patients with pulmonary embolism. Eur Heart J 2006; 27: 476-481.

10 Aujesky D, Obrosky DS, Stone RA, et al. A prediction rule to identify low-risk patients with pulmonary embolism. Arch Intern Med 2006; 166: 169-175.

11 Kucher N, Luder CM, Dörnhöfer T, Windecker S, Meier B, Hess OM. Novel management strategy for patients with suspected pulmonary embolism. Eur Heart J 2003; 24: 366-376.

12 Arcelus JI, Caprini JA, Monreal M, Suárez C, GonzálezFajardo JA. The management and outcome of acute venous thromboembolism: a prospective registry including 4011 patients. J Vasc Surg 2003; 38: 916-922.

13 Trujillo-Santos J, Perea-Milla E, Jiménez-Puente A, et al. Bed rest or ambulation in the initial treatment of patients with acute deep vein thrombosis or pulmonary embolism: findings from the RIETE registry. Chest 2005; 127: 1631-1636.

14 Barba R, Marco J, Martín-Alvarez H, et al. The influence of extreme body weight on clinical outcome of patients with venous thromboembolism: findings from a prospective registry (RIETE). J Thromb Haemost 2005; 3: 856-862.

15 Monreal M, Falgá C, Valle R, et al. Venous thromboembolism in patients with renal insufficiency: findings from the RIETE Registry. Am J Med 2006; 119: 1073-1079.

16 Trujillo-Santos J, Herrera S, Page MA, et al. Predicting adverse outcome in outpatients with acute deep vein thrombosis: findings from the RIETE Registry. J Vasc Surg 2006; 44: 789-793.

17 Cockcroft DW, Gault MH. Prediction of creatinine clearance from serum creatinine. Nephron 1976; 16: 31-41.

18 Hanley JA, McNeil BJ. The meaning and use of the area under a receiver operating characteristic (ROC) curve. Radiology 1982; 143: 29-36.

19 Wells PS, Kovacs MJ, Bormanis J, et al. Expanding eligibility for outpatient treatment of deep venous thrombosis and pulmonary embolism with low-molecularweight heparin: a comparison of patient self-injection with homecare injection. Arch Intern Med 1998; 158: 1809-1812.

20 Wells PS, Anderson DR, Rodger MA, et al. A randomized trial comparing 2 low-molecular-weight heparins for the 
outpatient treatment of deep vein thrombosis and pulmonary embolism. Arch Intern Med 2005; 165: 733-738.

21 Wan S, Quinlan DJ, Agnelli G, Eikelboom JW. Thrombolysis compared with heparin for the initial treatment of pulmonary embolism: a meta-analysis of the randomized controlled trials. Circulation 2004; 110: 744-749.

22 Agnelli G, Becattini C, Kirschtein T. Thrombolysis versus heparin in the treatment of pulmonary embolism: a clinical outcome-based meta-analysis. Arch Intern Med 2002; 162: 2537-2541.

23 Dalen JE. The uncertain role of thrombolytic therapy in the treatment of pulmonary embolism. Arch Intern Med 2002; 162: 2521-2523.

24 Goldhaber SZ, Elliott CG. Acute pulmonary embolism: part II. Risk stratification, treatment, and prevention. Circulation 2003; 108: 2834-2838.

25 Konstantinides S, Geibel A, Heusel G, Heinrich F, Kasper W, Management Strategies and Prognosis of Pulmonary
Embolism-3 Trial Investigators. Heparin plus alteplase compared with heparin alone in patients with submassive pulmonary embolism. N Engl J Med 2002; 347: 1143-1150.

26 Buller HR, Sohne M, Middeldorp S. Treatment of venous thromboembolism. J Thromb Haemost 2005; 3: 1554-1560.

27 Schoepf UJ, Kucher N, Kipfmueller F, Quiroz R, Costello P, Goldhaber SZ. Right ventricular enlargement on chest computed tomography: a predictor of early death in acute pulmonary embolism. Circulation 2004; 110: 3276-3280.

28 Goldhaber SZ, Visani L, De Rosa M. Acute pulmonary embolism: clinical outcomes in the International Cooperative Pulmonary Embolism Registry (ICOPER). Lancet 1999; 353: 1386-1389.

29 Konstantinides S, Geibel A, Olschewski M, et al. Association between thrombolytic treatment and the prognosis of hemodynamically stable patients with major pulmonary embolism: results of a multicenter registry. Circulation 1997; 96: 882-888. 